\title{
Exploration of Immunology: challenging knowledge, developing curiosity and transforming passion into discovery
}

\author{
Dominique J Charron ${ }^{1,2,3}{ }^{*}$, Reem Al-Daccak ${ }^{1}$ (D) \\ ${ }^{1}$ Human Immunology Pathophysiology Immunotherapy, Inserm U976, Université de Paris, Hôpital Saint-Louis, APHP, 75010 \\ Paris, France \\ ${ }^{2}$ Department of Immunology and Hematology, Inserm U1109, Université de Strasbourg, 67000 Strasbourg, France \\ ${ }^{3}$ Jiao Tong University Ruijin Hospital, Shanghai 200025, China
}

${ }^{*}$ Correspondence: Dominique J Charron, Inserm U976, Bâtiment Bazin Hôpital Saint-Louis,1 av Claude Vellefaux, 75010 Paris, France.d.charron.sls@gmail.com

Academic Editor: Dominique J Charron, Hôpital Saint-Louis, France; Reem Al-Daccak, Hôpital Saint-Louis, France

Received: November 5, 2020 Accepted: November 6, 2020 Published: April 30, 2021

Cite this article: Charron DJ, Al-Daccak R. Exploration of immunology: challenging knowledge, developing curiosity and transforming passion into discovery. Explor Immunol. 2021;1:1-3. https://doi.org/10.37349/ei.2021.00001

When launching a new journal for Immunology, the title is the first impression that emphasizes the promise of a distinct identity and discloses its own innovative spirit and aim.

Exploration, precisely highlights the idea of an authentic and powerful tool for developing creative, reliable, and trustworthy new knowledge. Immunology, is a real challenge amply echoed in Socrates' most famous paradox "I know that I know nothing". Within this spirit, the new Exploration of Immunology is intended to be a forum of high-quality open-source free-access knowledge in immunology. As such it will offer an integrated vision of current Immunology to the global scientific, medical, biotech, and social communities contributing thus, to the development of the open science of Immunology.

The earliest description of the concept of immunity belonged to ancient times [1]. The General and

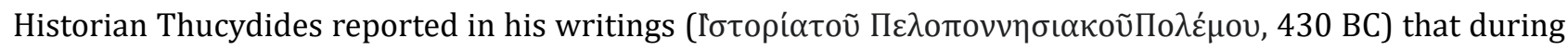
the Peloponnesian war, those who survived the plague were out of danger even during an ongoing epidemy whereas in ancient China, variolation was used as a protective measure against smallpox. Macroscopic Exploration afterwards localized the anatomical sites and described the tissues and organs involved in an immune status. The identification of tissues cellular composition and fine architecture, through microscopic Exploration, revealed then that immunity is not ascribed to a unique organ localized at a single site, but rather a phenomenon with multiple distinct players as well illustrated in the discovery path of early vaccines by Edward Jenner and Louis Pasteur.

We knew about immunity long before knowing about Immunology. It took over twenty centuries for Immunology to develop into a scientific theory and for Elie Metchnikoff to coin the word around 1900. Analytical Exploration of the molecular and cellular contributors and their interactive networks, signals, and crosstalk allowed over the 20th century to define immunity as a wholly integrated system displaying a high degree of connectivity but also established the self/non-self paradigm of Immunology. While the later defined one's biological identity, the cognitive nature of functional immune response advanced the concept of individuality within species and populations $[2,3]$. 
The 21st century high-throughput multi-omics, in vivo imaging, bioinformatics, and computing innovative technics advanced the contemporary Exploration of immune physiology and pathology, which is now attainable at the single cell level in vitro as well as in the whole organism in vivo [4]. How the immune homeostasis is maintained? How metabolic pathways are coupled to immune function? How the environmental components (microbiota, nutrients, climate, lifestyle...) interact to shape the immune processes at the individual and population levels? are all leading questions that are paving the way towards an ecological cohesive and ultimately holistic intelligence of Immunology.

The many challenges to integrate Immunology and to leverage immune scientific discoveries for the benefit of humankind are yet to be confronted. The generation of inclusive knowledge in Immunology needs to be collectively accelerated to reach a more universal level. Open science [5] is fundamental to develop the 21st century biology and medicine; an approach pioneered by immunologists and geneticists through the organization of the International Histocompatibility (HLA) Workshops since 1964 [6] and the launch of the Human Genome Organization in 1988 [7]. While initially the implication of Immunology in medicine only concerned infectious diseases, it was extended over the 20th century to auto-immune diseases and transplant rejection. Emerging as a multidisciplinary and integrative multiscale field, Immunology is today crucial to all medical practice standing at the forefront of contemporary medicine in translating basic science into novel therapeutics. As mainstream, Immunology is empowered to develop valuable innovative biomarkers and algorithms not only for diagnosis and advanced biotherapies in cancer, inflammatory diseases, degenerative disorders, but also for aging. Therefore, it is integral to societal and well-being health policies.

Every scientist, physician, and health worker in their daily practice will have to further Explore Immunology while every person may benefit from the fast-track immunological knowledge for predictive, preventive, and increasingly curative medicine. All, so well-illustrated in the current COVID-19 pandemic disease with its load of progress and debates [8].

The Editorial team of Exploration of Immunology is fully dedicated and energized to work with the community of immunologists to develop Exploration of Immunology to fulfill the fascination we all have to advance the Immunology of the future in an open-science philosophy.

"Exploration is what you do when you don't know what you are doing. That's what scientists do every day."

Neil de Grasse-Tyson

\section{Declarations}

\section{Conflicts of interest}

The authors declare that they have no conflicts of interest.

\section{Ethical approval}

Not applicable.

\section{Consent to participate}

Not applicable.

\section{Consent to publication}

Not applicable.

\section{Availability of data and materials}

Not applicable.

\section{Funding}

Not applicable. 


\section{Copyright}

(c) The Author(s) 2020.

\section{References}

1. Kaufmann SHE. Immunology's coming of age. Front Immunol. 2019;10:684.

2. Swiatczak B, Tauber AI. Philosophy of immunology. In: Zalta EN, editor. The stanford encyclopedia of philosophy. Summer 2020 ed. Stanford: Metaphysics Research Lab, Stanford University; 2020.

3. Pradeu T. Philosophy of immunology. Cambridge: Cambridge University Press; 2020.

4. Weinmann AS, Youngblood BA, Smale ST, Brink R, Schatz DG, McHeyzer-Williams M. A future outlook on molecular mechanisms of immunity. Trends Immunol. 2020;41:549-55.

5. Woelfle M, Olliaro P, Todd MH. Open science is a research accelerator. Nat Chem. 2011;3:745-8.

6. Charron D. Genetic diversity of HLA, functional and medical implications. 1st ed. Paris: EDK; 1997.

7. Liu ET. The human genome organization (HUGO). Hugo J. 2009;3:3-4.

8. Dhillon P, Breuer M, Hirst N. COVID-19 breakthroughs: separating fact from fiction. FEBS J. 2020;287:3612-32. 